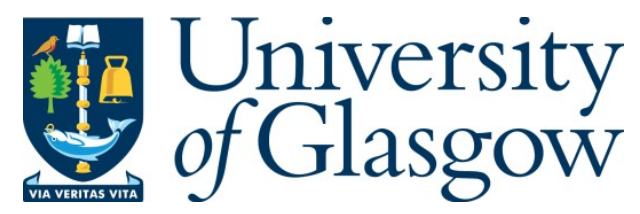

Ruan, S., Zhu, W., Yang, E.-H., Weng, Y. and Unluer, C. (2020) Improvement of the performance and microstructural development of alkali-activated slag

blends. Construction and Building Materials, 261, 120017.

(doi: 10.1016/j.conbuildmat.2020.120017)

This is the Author Accepted Manuscript.

There may be differences between this version and the published version. You are advised to consult the publisher's version if you wish to cite from it.

https://eprints.gla.ac.uk/219601/

Deposited on: 17 February 2021

Enlighten - Research publications by members of the University of Glasgow http://eprints.gla.ac.uk 


\section{Improvement of the performance and microstructural development of alkali-activated slag blends}

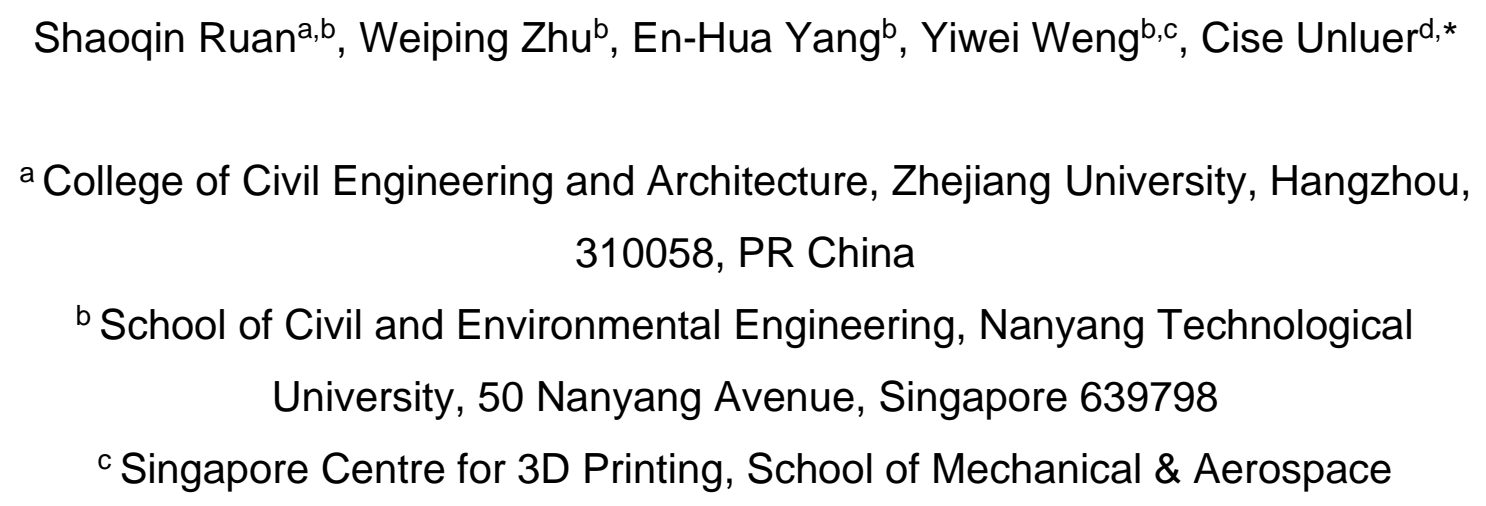

Abstract: This study investigated the performance and microstructural development of alkali-activated slag (AAS) blends containing hydromagnesite seeds. AAS blends with and without seeds were assessed by isothermal calorimetry, porosity, setting time and compressive strength measurements. The formation of hydrate phases was further investigated via XRD, TGA-DSC, FTIR and SEM analyses. AAS blends incorporating $2 \%$ hydromagnesite seeds revealed the best performance in terms of hydration kinetics, strength and microstructural development. The positive influence of seeds was highlighted via increased hydration rates and degrees, shortened setting times, higher compressive strengths and denser microstructures. These improvements were attributed to the provision of additional nucleation sites in the presence of seeds that enabled the increased formation of hydrate phases (e.g. C-(A)-S-H with more crosslinks forming between adjacent silicate chains) within the pore structure. 
31 Keywords: Alkali activated cement; kinetics; calcium-silicate-hydrate;

32 performance; microstructure 


\section{Introduction}

Alkali-activated cements (AACs) are being investigated as an alternative to ordinary Portland cement (OPC), due to the improvements they offer in terms of long-term chemical resistance and lower environmental impact associated during their production [1-3]. Recent studies looked into the use of AACs in foamed products [4] and 3D printed composites [5, 6]. Ground granulated blast-furnace slag (GGBS), produced by quenching molten iron slag from a blast furnace, has been widely used since the emergence of AACs [1]. Different activators such as sodium hydroxide and sodium silicate provide a high $\mathrm{pH}$ and thereby increase the solubility and dissolution of slag. This activation process facilitates the formation of hydrate phases such as C-(A)-S-H [7], resulting in a high mechanical performance and chemical resistance [1]. However, some drawbacks of AACs are still present, such as their susceptibility to drying shrinkage at room temperature, whereas recent studies [8] reported a reduction in total drying shrinkage with the inclusion of certain additives such as polyethylene glycol.

AACs can be considered under calcium- and silica-based and aluminosilicatebased systems. The rate and degree of hydration and the morphology of phases forming in AAS blends determine their mechanical properties due to the formation

53 of different phases [2, 9]. Similar to the hydration of OPC, the hydration of slag under a high $\mathrm{pH}$ environment (e.g. > 12) involves the stages of dissolution, induction, acceleration, deceleration and steady state diffusion [10]. However, during this process, the initially formed hydrate phases could create a layer and cover the surface of unreacted slag particles, which slows down the reaction and leads to a lower overall hydration degree.

One possible solution to this limitation in hydration involves the use of seeds in the initial mix design. These seeds can act as nuclei for the increased precipitation of

62 hydrate phases. Because of its influence in accelerating the hydration kinetics of cementitious materials, nucleation seeding can be an effective approach in 
enhancing the formation of hydrate phases at early ages [11]. A few studies

65 investigated the effect of seeding in cementitious systems. These involved the use of synthesized C-S-H seeds as nucleation sites in OPC and pure tricalcium silicate $\left(\mathrm{C}_{3} \mathrm{~S}\right)$ pastes [12], as well as AAS blends [13]. The obtained results revealed the benefits of seeding in the acceleration of hydration kinetics via the increased nucleation and growth of hydrate phases, which was previously identified as the rate limiting step during the hydration process. This led to an improved strength

71 development at both early and later stages $[12,13]$.

Alternatively, recent studies [14] reported that while the synthesized C-S-H seeds played a role in the further precipitation of $\mathrm{C}-(\mathrm{A})-\mathrm{S}-\mathrm{H}$, they did not necessarily facilitate the formation of the geopolymer gel. To obtain the $\mathrm{C}-\mathrm{S}-\mathrm{H}$ gel that is introduced into the mix for seeding purposes, the main method followed in the literature involves its synthesis through the reaction of sodium silicate and calcium

78 nitrate [15] or calcium hydroxide and nano-silica [16] in a laboratory environment. This process is composed of several steps involving the washing, filtering and drying of the synthesized material, which is time consuming and is prone to carbonation when exposed to air [15]. Furthermore, differences in the $\mathrm{Ca} / \mathrm{Si}$ ratio of C-S-H can influence the formation and properties of hydrate phases in the mixes it is introduced in [16], thereby limiting its use on a large scale in practice.

In addition to C-S-H, some nano particles were also involved as nucleation seeds due to their large surface areas [11, 17]. For instance, the use of nano-silica in OPC increased the hydration degree and rate, which was determined by the measurement of total surface area and calcium concentration [17]. Another study [18] revealed the catalytic effects of nano- $\mathrm{Al}_{2} \mathrm{O}_{3}$ particles in geopolymer mixes, which enabled an increased amount of gel phase formation within a short period of time due to their large surface areas. In addition to nano- $\mathrm{Al}_{2} \mathrm{O}_{3}$, the nucleation and filling effects of nano- $\mathrm{CaCO}_{3}$ and nano- $\mathrm{SiO}_{2}$ were also reported in $\mathrm{PC}$-based mixes that revealed a more compact and homogeneous structure [19]. Similarly, the use of nano clay [20] and nano metakaolin [21] also contributed to the strength 
development of PC mixes. A similar effect was found in samples containing polycarboxylates, which can be an alternative admixture for improving the strength of concrete mixes [22]. Further studies [23-25] indicated that seeding was also effective in enhancing the hydration process in calcium-free binder systems. However, nano materials can pose a threat to human health and have a very high cost, presenting a challenge in their use in large scale applications [26, 27].

Other than nano materials, the use of hydromagnesite $\left(4 \mathrm{MgCO}_{3} \cdot \mathrm{Mg}(\mathrm{OH})_{2} \cdot 4 \mathrm{H}_{2} \mathrm{O}\right)$ as an additive in cement-based mixes has also been investigated [23, 28]. Other studies [29] looked into the influence of $\mathrm{Mg}^{2+}$ on the kinetics of calcite precipitation and morphology. While it can be synthetically produced [30, 31], hydromagnesite is a naturally occurring mineral and is related to other magnesium containing minerals such as serpentine, dolomite and brucite [32]. Furthermore, its lower commercial cost than many of the nano materials such as nano- $\mathrm{SiO}_{2}, \mathrm{TiO}_{2}$ and $\mathrm{Al}_{2} \mathrm{O}_{3}$ presents a benefit for the use of hydromagnesite. Unlike the hydration of pure $\mathrm{MgO}$ that leads to the formation of brucite, which does not result in a significant strength gain, a boost in the compressive strength of $\mathrm{MgO}$ mixes was seen in the presence of hydromagnesite [33]. Within these MgO-hydromagnesite blends, the formation of an amorphous phase was observed, which could contribute to their cohesive binding [34]. A similar outcome was observed in AAS mixes, where the combined used of $\mathrm{MgO}$ and hydromagnesite led to improved performance via the adjustment of the $\mathrm{pH}$ to accelerate the dissolution of GGBS [28].

Differing from the existing literature, this paper focuses on the incorporation of various amounts of hydromagnesite in AAS blends with the goal of identifying its effect on hydration kinetics and associated performance, which has not been investigated before. To reveal the role of hydromagnesite seeds in the improvement of reaction mechanisms, sample performance and microstructural development, the seeded samples were compared with the precursor (i.e. slag blend without any activator or seed) and unseeded AAS blends via the use of 
126 different analysis techniques. The effect of nucleation seeding was evaluated by

127 isothermal calorimetry, setting time, porosity and compressive strength 128 measurements. X-ray diffraction (XRD), thermogravimetric analysis and 129 differential scanning calorimetry (TGA-DSC), Fourier transform infrared 130 spectroscopy (FTIR) with spectral subtraction and deconvolution, and scanning 131 electron microscopy (SEM) were used in the analysis of the hydration process and 132 the assessment of the amount and morphology of hydrate phases in both seeded 133 and unseeded samples.

2. Materials and Methodology

\subsection{Materials and sample preparation}

140 The GGBS used in this study, whose chemical composition (i.e. obtained from the 141 supplier, Engro Corporation Ltd. (Singapore)) is shown in Table 1, was grade 142 P8000, referring to a super-reactive ultrafine slag powder (average particle size: < $1435 \mu \mathrm{m}$ and fineness: $800-900 \mathrm{~m}^{2} / \mathrm{kg}$, which is $2-3$ times higher than common GGBS). 144 In line with the findings of a previous study [13], the activator used was sodium 145 metasilicate pentahydrate $\left(\mathrm{NaSiO}_{3} \cdot 5 \mathrm{H}_{2} \mathrm{O},>97 \%\right)$, obtained from VWR Pte. Ltd. 146 (Singapore). The activator was included at $10 \%$ of the mass of the binder (slag). 147 In terms of seeds, hydromagnesite $\left(4 \mathrm{MgCO}_{3} \cdot \mathrm{Mg}(\mathrm{OH})_{2} \cdot 4 \mathrm{H}_{2} \mathrm{O}\right.$, specific surface area 148 (SSA): $43.5 \mathrm{~m}^{2} / \mathrm{g}$ ) was obtained from Fisher Scientific Ltd. (UK). Different amounts 149 of hydromagnesite, corresponding to 1,2 and $5 \%$ of the mass of the binder 150 component, were used. The morphology of hydromagnesite presented in Fig. 1 151 demonstrated a rosette-like structure, which was in line with those reported in 152 previous studies [35-38].

153

154 The prepared fresh mixture was cast into $50 \times 50 \times 50 \mathrm{~mm}$ cubic molds, consolidated 155 by a vibrating table and finished by a trowel. All samples were demolded after 24 
156 hours and cured under ambient temperature $\left(30 \pm 1.5^{\circ} \mathrm{C}\right)$ and relative humidity $157(80 \pm 5 \%)$.

2.2 Methodology

\subsubsection{Isothermal calorimetry}

The heat flow corresponding to the hydration of AAS blends was investigated at $30^{\circ} \mathrm{C}$ by an I-Cal 2000 high precision calorimeter according to ASTM C1702-17 [39]. To prepare the paste samples, hydromagnesite seeds were first dispersed in the $\mathrm{NaSiO}_{3} \cdot 5 \mathrm{H}_{2} \mathrm{O}$ solution by an ultrasonic homogenizer (Q500 sonicator), followed by the mixing of the slag into the solution, which was previously heated to $30^{\circ} \mathrm{C}$ (i.e. room temperature). Once the prepared pastes were ready, they were immediately placed into the calorimeter to record the heat released for up to 36 hours.

\subsubsection{Setting time}

175

176 The setting time of AAS blends was evaluated by the measurement of the penetration depth of the Vicat needle into the prepared pastes in accordance with ASTM C191-08 [40]. The initial setting time was calculated to the nearest 1 minute according to Equation 1, where E represented the time (minutes) of the last penetration greater than $25 \mathrm{~mm}, \mathrm{H}$ represented the time (minutes) of the first penetration less than $25 \mathrm{~mm}, C$ represented the penetration reading at time $E$ and $D$ represented the penetration reading at time $\mathrm{H}$. The final setting time, calculated to the nearest 5 minutes, was determined by the time that elapsed between the 184 initial contact of water and cement and the time that the needle was unable to sink 185 visibly. 
187 Initial setting time $=((\mathrm{H}-\mathrm{E}) /(\mathrm{C}-\mathrm{D})) \cdot(\mathrm{C}-25)+\mathrm{E}$

\subsubsection{Porosity}

X-ray computed tomography $(\mu-C T)$, performed with a SkyScan1183 scanner, a camera, and a flat panel sensor, was employed to analyze the porosity of the prepared blends, including the open and closed pores. Unlike other methods such as Mercury Intrusion Porosimetry (MIP), where the pore distribution is highly influenced by the intrusion pressure, $\mu-C T$ is capable of accurately revealing the pore volume and size distribution without damaging the sample [41]. To facilitate this, the specimens obtained from samples crushed during strength testing were fixed on a micro-positioning stage and scanned using a source voltage and current of $80 \mathrm{kV}$ and $100 \mu \mathrm{A}$, respectively. The analysis of porosity involved the process of image acquisition, reconstruction, thresholding, pore labelling and quantification. During image acquisition, a representative 2D projection of each sample (i.e. at a diameter of $25 \mathrm{~mm}$ and spatial resolution of $7 \mu \mathrm{m}$ ) was selected. The thresholding, pore labelling and quantification of porosity were conducted with the CT-Analyzer software.

\subsubsection{Compressive strength}

The compressive strength of AAS blends was tested at 3, 7 and 14 days. The test was conducted using a compression machine (Toni Technik Baustoffprüfsysteme

$212 \mathrm{GmbH}$ ), operated at a constant loading rate of $100 \mathrm{kN} / \mathrm{min}$. The average and 213 standard deviation of three samples were reported for each data point. 
218 Hardened paste specimens extracted from the cubic samples crushed after 219 strength testing were stored in acetone to stop hydration and dried under vacuum 220 for 24 hours to prepare for microstructural analysis. Prior to microstructural 221 analysis, the vacuum dried samples were ground down to pass through a $75 \mu \mathrm{m}$ 222 sieve.

223

XRD was recorded on a Philips PW 1800 spectrometer using Cu $\mathrm{K}_{\alpha}$ radiation (40 $225 \mathrm{kV}, 30 \mathrm{~mA}$ ) with a scanning rate of $2^{\circ} 2 \theta$ /step from $5^{\circ}$ to $80^{\circ}(2 \theta)$. TGA-DSC was conducted on a Perkin Elmer TGA 4000 equipment from 30 to $900^{\circ} \mathrm{C}$ with a heating 227 rate of $10^{\circ} \mathrm{C} / \mathrm{min}$ under nitrogen flow.

A Thermo Scientific Nicolet iS50 spectrometer with a built-in attenuated total reflection (ATR) module was used to obtain Fourier transform infrared spectroscopy (FTIR) spectra and identify the chemical components within the samples. Prior to analysis in the transmittance mode, the preparation of a pellet was conducted consisting of a mixture of $1 \mathrm{mg}$ of powder from the samples with $300 \mathrm{mg}$ of $\mathrm{KBr}$. The mixture was pressed using 7 metric tons of hydraulic pressure 235 in a die. In the ATR mode, powder samples were placed directly on the diamond ATR sampling station and pressed against the diamond crystal by a constant compressive force of $267 \mathrm{~N}$. The resolution was set at $4 \mathrm{~cm}^{-1}$ and a collection of 64 scans was obtained for each spectrum. Spectral subtraction and deconvolution

Before SEM analysis, samples were vacuum dried for 24 hours and coated with 242 platinum under a $30 \mathrm{~mA}$ current, with a coating time of 30 seconds. The coated 243 samples were then studied via a field emission scanning electron microscope 244 (FESEM, 207 JOEL JSM-7600F). Backscattered electron (BSE) imaging was also used in SEM. To facilitate this, the vacuum dried samples were mounted in epoxy resin for 24 hours and polished to obtain smooth surfaces. Initial polishing was 2489,3 and $0.3 \mu \mathrm{m}$. Dust and diamond particles generated during the polishing 
249 process were removed by exposing the samples to an ultrasonic bath for 10

250 minutes, followed by vacuum drying for another 24 hours before the analysis.

\section{$253 \quad 2.2 .6 \mathrm{pH}$ test}

254

The $\mathrm{pH}$ values of the activator and hydromagnesite seeds were measured via a 256 calibrated Mettler Toledo pH meter, in line with ASTM C25 [43]. Accordingly, 5 257 grams of powder was blended with 100 grams of distilled water for 30 min prior to 258 each test.

\section{Results}

\subsection{Isothermal calorimetry}

The heat flow curves showing the reaction of AAS blends containing different 266 amounts (i.e. $1-5 \%$ of the binder content by mass) of hydromagnesite during the first 36 hours are presented in Fig. 2. The hydration of GGBS by itself did not release any noticeable amount of heat, as indicated by the relatively flat heat curve.

269 This was attributed to the low pH of this system, limiting the dissolution of the binder. Alternatively, when activated by the high pH provided by $\mathrm{Na}_{2} \mathrm{SiO}_{3} \cdot 5 \mathrm{H}_{2} \mathrm{O}$, all AAS blends indicated notable hydration peaks, albeit at different times and 272 intensities. The common aspect of all AAS blends was the three stages of the 273 hydration process. The first stage was the pre-induction stage, associated with the 274 dissolution of slag [44]. The length and the timing of this stage depended on the 275 type of the seed. The second stage was the induction period, which was 276 significantly shortened due to the availability of a large number of nuclei provided 277 by the presence of the seeds. The third stage of hydration was the nucleation, 278 growth and precipitation of the hydrate phases. When compared to the unseeded 279 blends, the advances in the hydration of blends containing seeds were associated 
with the provision of additional nucleation sites supplied by the seeds within the pore space, away from the particle surfaces [12].

Increasing the amount of hydromagnesite seed from $1 \%$ to $2 \%$ led to an obvious reduction in the induction period and enabled the acceleration of the hydration reaction. A further increase in the seed content to $5 \%$ delayed the appearance of the main hydration peak when compared to blends containing $2 \%$ seed. This adverse effect could be associated with the agglomeration of the seed when its quantity was increased, which was in line with the observations reported in previous studies [24]. Accordingly, the high amount of seeds used in these blends could have led to the trapping of the alkali solution within the solid particles, thereby limiting the dissolution of the main binder phase. Therefore, hydromagnesite seed included at $2 \%$ of the overall binder content was chosen in the preparation of further mixes, whose details are shown in Table 2.

\subsection{Setting time}

The initial and final setting time of all samples are presented in Fig. 3. The setting of all mixes generally took place during the acceleration period. In line with the isothermal calorimetry results, the sample without any activator or seed $(\mathrm{GAOHO})$ demonstrated a very long setting time, which was associated with the initially low alkalinity of the pore solution. The incorporation of $10 \%$ activator in sample $\mathrm{GA} 10 \mathrm{H} 0$ led to an obvious reduction in both the initial and the final setting times due to the increase in the $\mathrm{pH}$ of the solution, which enabled the dissolution of the binder and the precipitation of hydrate phases responsible for setting. The use of seeds along with the activator in sample GA10H2 had a much more significant effect on setting time, which was largely reduced. This notable reduction in the setting time was associated with the provision of nucleation sites via the addition of hydromagnesite. This led to an elimination of the induction period, thus reducing the setting time. Furthermore, the presence of hydromagnesite, which acted as 
311 nuclei within the pore solution, favored the formation of a higher amount of hydrate

312 phases, which led to the rapid hardening of sample GA10H2. These findings were

313 in line with those of previous studies [45], where it was indicated that the

314 incorporation of fine carbonate fillers led to a rapid increase in viscosity due to the

315 improvement of the packing density of cement-based systems, resulting in shorter

316 setting times in seeded samples.

\subsection{Porosity}

320

321 The typical 2D images of cross-sections (i.e. diameter $=25 \mathrm{~mm}$; spatial resolution

$322=7 \mu \mathrm{m}$ ) and corresponding porosities (i.e. shown in the lower left corner of each 323 image) of all samples after 14 days of curing are presented in Fig. 4. Since $\mu$-CT 324 analysis is known to enable the identification and quantification of both closed and open pores within the samples [46], the obtained results were a clear indication of the significant decline in porosity facilitated by the introduction of seeds in the sample $\mathrm{GA} 10 \mathrm{H} 2$, where the volume taken up by solid phases was notably increased. This effect was attributed to the seeding effect of hydromagnesite particles, which enabled the abundant formation of hydrate phases within the pore solution. This could be further supported with the micro-filler effect of the seed itself, whose physical presence reduced the void space between large particles [47], 332 albeit at a much smaller scale than the seeding effect. The micro-filler effect was 333 not identified as the major cause of porosity reduction as the porosity of sample $334 \mathrm{GA} 10 \mathrm{H} 2$ was 3.5 times smaller than that of sample $\mathrm{GA} 10 \mathrm{H} 0$ (i.e. $16.9 \%$ vs. $59.7 \%$ ), in the presence of only $2 \%$ hydromagnesite seeds by weight.

\subsection{Compressive strength}

Fig. 5 presents the early strength development of all samples up to 14 days. All samples revealed a stable increase in strength with curing age due to the 
342 continuation of hydration. Activated $(\mathrm{GA} 10 \mathrm{H} 0)$ and seeded $(\mathrm{GA} 10 \mathrm{H} 2)$ samples 343 revealed higher 3-day strengths (17.1-19.1 MPa) than the control sample (GAOHO, $34411.9 \mathrm{MPa}$ ). The notable strength of the control sample without the use of any 345 activator or seeds could be associated with the relatively high reactivity and 346 fineness of the GGBS used in this study. A similar trend was also observed at 347 longer curing periods, during which the effect of seeding became more prominent. 348 In line with the hydration kinetics and porosity results, the introduction of $10 \%$ of 349 activator in sample $\mathrm{GA} 10 \mathrm{H} 0$ led to $~ 30 \%$ improvement in strength at 14 days due 350 to the increase in the dissolution of slag in the alkaline environment. While the 3351 day strengths of samples $\mathrm{GA} 10 \mathrm{H} 0$ and $\mathrm{GA} 10 \mathrm{H} 2$ were comparable, an increase in 352 the curing age resulted in an obvious improvement in the strength of the seeded 353 sample. Accordingly, sample $\mathrm{GA} 10 \mathrm{H} 2$ revealed a 14-day strength of $38.3 \mathrm{MPa}$, 354 which was $71.7 \%$ higher than that of sample GA10H0 (22.3 MPa). This 355 improvement in the presence of seeds was associated with the formation of a 356 continuous network of hydrate phases around the solid particles within the pore 357 solution. Without the addition of seeds, the precipitation of hydrate phases was 358 restricted by the limited content of solid phases within the slag, whose surface area 359 gradually reduced as hydrate phases started growing around them. Alternatively, 360 the provision of additional nucleation sites enabled the further deposition of hydrate 361 phases on the nuclei as well, which was reflected as improved performance in 362 sample GA10H2 when compared to other samples. This could be further enhanced 363 with the filler effect of the seed, which contributed to the densification of sample 364 microstructure, and hence increased the strength in the long term.

369 Fig. 6 presents the XRD patterns of all samples after 14 days of curing. The broad 370 hump located at around $25-35^{\circ} 2 \theta$ observed in sample GAOHO was attributed to 371 the presence of amorphous phases [48], whereas with the introduction of activator 372 in samples $\mathrm{GA} 10 \mathrm{H} 0$ and $\mathrm{GA} 10 \mathrm{H} 2$ led to the appearance of $\mathrm{C}-(\mathrm{A})-\mathrm{S}-\mathrm{H}$ at $30-31^{\circ} 2 \theta$ 
373 (PDF \#00-033-0306) as the major hydrate phase, which was in line with the 374 findings of previous studies [49]. The XRD pattern of sample $\mathrm{GA} 10 \mathrm{H} 2$ also 375 demonstrated the presence of hydrotalcite $\left(\mathrm{Mg}_{6} \mathrm{Al}_{2}(\mathrm{OH}){ }_{16} \mathrm{CO}_{3} \cdot 4 \mathrm{H}_{2} \mathrm{O}\right.$; PDF \#01376 070-2151), however at a lower intensity when compared with C-(A)-S-H. The $\mathrm{Mg}^{2+}$ 377 source in hydrotalcite could be due to the dissolution of the slag. Alternatively, the 378 presence of calcite in samples $\mathrm{GA} 10 \mathrm{H} 0$ and $\mathrm{GA} 10 \mathrm{H} 2$ ( $\mathrm{CaCO}_{3}$; PDF \#01-071-3699) 379 could be attributed to the reaction between $\mathrm{Ca}^{2+}$ (i.e. from the dissolution of slag) 380 and atmospheric $\mathrm{CO}_{2}$ via natural carbonation (Equation 2), albeit small due to the 381 low concentration of $\mathrm{CO}_{2}$ in the atmosphere ( $\left.0.04 \%\right)$. The absence of any obvious 382 hydromagnesite peaks in the XRD patterns was due to the low contents of 383 hydromagnesite (i.e. $2 \%$ of the binder content) present in the seeded samples, as 384 well as the precipitation of hydrate phases around the seed particles. Overall, the 385 XRD patterns confirmed that the formation of hydrate phases such as C-(A)-S-H 386 was associated with the strength development of the seeded samples.

387

388

$\mathrm{Ca}^{2+}+\mathrm{CO}_{3}^{2-} \rightarrow \mathrm{CaCO}_{3}$

\subsection{TGA-DSC}

392

The TGA-DSC results of all samples after 14 days curing are shown in Fig. 7. The following three stages of thermal decomposition were observed:

(i) $30-220^{\circ} \mathrm{C}$ : Mass loss due to the dehydration of $\mathrm{C}-(\mathrm{A})-\mathrm{S}-\mathrm{H}$, with an endothermic 397 peak at $\sim 80^{\circ} \mathrm{C}[49]$.

398

399

(ii) $220-730^{\circ} \mathrm{C}$ : Mass loss due to the decomposition of hydrotalcite $[49,50]$.

400

401

402

(iii) $730-900^{\circ} \mathrm{C}$ : Mass loss due to the decarbonation of carbonates (e.g. calcite), 403 
404 The summary of mass loss values obtained at various stages of thermal 405 decomposition after 14 days of curing is shown in Table 3. The bound water 406 content calculated from the mass loss in C-(A)-S-H could be used as an 407 assessment of the hydration degree in cement blends [50,52]. In line with the XRD 408 results, the introduction of seeds in sample GA10H2 revealed $\sim 130 \%$ increase in 409 the mass loss when compared with unseeded samples. Furthermore, the sharper 410 endothermic peak observed at $\sim 80^{\circ} \mathrm{C}$ in sample $\mathrm{GA} 10 \mathrm{H} 2$ also hinted the presence 411 of a higher amount of C-(A)-S-H than in other samples. Similarly, a slightly higher 412 amount of mass loss corresponding to the decomposition of hydrotalcite was 413 observed in sample $\mathrm{GA} 10 \mathrm{H} 2$. The overall decomposition patterns revealed by all 414 samples highlighted the higher contents of hydrate phases, especially $\mathrm{C}-(\mathrm{A})-\mathrm{S}-\mathrm{H}$, 415 in samples involving the simultaneous use of activator and seeds. These outcomes 416 were in line with the XRD patterns, as well as the isothermal calorimetry, porosity 417 and strength measurements presented earlier.

\subsection{FTIR}

421

The FTIR spectra of the seed (hydromagnesite) and all samples after 14 days of 423 curing are shown in Fig. 8(a). The spectra of samples GA10H0 and GA10H2 424 revealed a peak at $800-1100 \mathrm{~cm}^{-1}$, which differed in shape and location (i.e. peak 425 center) when compared with sample GAOH0. This observation was attributed to 426 the stretching vibrations of Si-O $[53,54]$ due to the formation of $\mathrm{C}-(\mathrm{A})-\mathrm{S}-\mathrm{H}$ gel. 427 Furthermore, a low-intensity band around $590-600 \mathrm{~cm}^{-1}$ was demonstrated by 428 samples $\mathrm{GA} 10 \mathrm{H} 0$ and $\mathrm{GA} 10 \mathrm{H} 2$, indicating the presence of $\mathrm{C}-\mathrm{A}-\mathrm{S}-\mathrm{H}$ with the 429 incorporation of Al into C-S-H [55].

431 In order to identify the FTIR peaks of the hydrate phases in samples GA10H0 and $432 \mathrm{GA10H2}$, FTIR spectral subtraction [42] was conducted via subtracting the 433 spectrum of the control sample $(\mathrm{GAOH} 0)$ from the spectra of $\mathrm{GA} 10 \mathrm{H} 0$ and $\mathrm{GA} 10 \mathrm{H} 2$, 434 respectively (Fig. $8\left(\right.$ b)). As the band between $1080-1180 \mathrm{~cm}^{-1}$ was mainly due to 
435 the presence of unhydrated binder [42], the presence of hydrate phases could be 436 conservatively defined through spectral subtraction. The spectra of hydrate phases 437 in samples $\mathrm{GA} 10 \mathrm{H} 0$ and $\mathrm{GA} 10 \mathrm{H} 2$ (i.e. with baseline correction) were further 438 investigated by spectral deconvolution [42] to reveal the individual bands hidden 439 in the broad peaks. Fig. 9 presents these deconvolution results, which were used 440 to indicate the $\mathrm{Q}$ values of Si-O. In terms of various spectra assignments, the peak 441 around $860 \mathrm{~cm}^{-1}$ was assigned to $Q^{1}$ [56], whereas bands at 900 and $950-980 \mathrm{~cm}^{-}$ $442{ }^{1}$ were unanimously assigned to stretching vibrations of $Q^{2}$ sites $[57,58]$. In line 443 with the findings of previous studies [42, 59,60], the peaks at 898, 947 (945) and $444985 \mathrm{~cm}^{-1}$ were assigned to $\mathrm{Q}^{2}$, as multiple $\mathrm{Q}^{2}$ sites could coexist in $\mathrm{C}-(\mathrm{A})-\mathrm{S}-\mathrm{H}$. The 445 deconvoluted spectra indicated that $\mathrm{Q}^{2}$ was the major band in both spectra. In 446 addition to the $\mathrm{Q}^{1}$ and $\mathrm{Q}^{2}$ assignments, the peak at $1030 \mathrm{~cm}^{-1}$ also indicated the 447 presence of crosslinked Si-O, which was allocated to $\mathrm{Q}^{3}$ [54] in C-A-S-H gels. 448 Along with the stretching vibrations of $\mathrm{Si}-\mathrm{O}$, the $872 \mathrm{~cm}^{-1}$ band at a position similar 449 to the bending band of $\mathrm{CO}_{3}{ }^{2-}$ was observed, which usually occurred at around 875 $450 \mathrm{~cm}^{-1}$ [58]. The noticeably higher peak intensities associated with $\mathrm{C}-(\mathrm{A})-\mathrm{S}-\mathrm{H}$ gel in 451 sample $\mathrm{GA} 10 \mathrm{H} 2$, as revealed by Fig. 9, were an indication of a higher yield of C452 A-S-H when compared to those of $\mathrm{GA} 10 \mathrm{H} 0$. This observation was in agreement 453 with the XRD and TGA findings, where an increased formation of hydrate phases 454 was revealed within sample $\mathrm{GA} 10 \mathrm{H} 2$ involving the simultaneous use of activator 455 and seeds.

Table 4 shows the FTIR spectral deconvolution of the hydrate phases in samples $458 \mathrm{GA} 10 \mathrm{H} 0$ and $\mathrm{GA} 10 \mathrm{H} 2$. While the total percentage of $\mathrm{Q}^{2}$ in the $\mathrm{C}-(\mathrm{A})-\mathrm{S}-\mathrm{H}$ gel 459 observed within both samples were similar, a greater percentage of $\mathrm{Q}^{3}$ sites in 460 sample $\mathrm{GA} 10 \mathrm{H} 2$ was observed. This difference highlighted a higher degree of 461 polymerization of the hydrate phase, referring to the presence of a more462 crosslinked $\mathrm{C}-(\mathrm{A})-\mathrm{S}-\mathrm{H}$ gel (i.e. revealing an improved polymerization of the 463 aluminosilicate skeleton) in sample $\mathrm{GA} 10 \mathrm{H} 2$ when compared to sample $\mathrm{GA} 10 \mathrm{H} 0$. 464 Moving on from previous studies [61], where it was shown that the formation of 465 crosslinked C-(A)-S-H was accountable for high strength gain in AAS blends, this 
466 finding could also contribute to the understanding of the improved reaction 467 mechanisms and associated performance of sample GA10H2.

\subsection{SEM}

471

472 Fig. 10 shows the microstructural images of selected samples after 14 days of 473 curing. When compared with the unseeded sample (GA10H0), the introduction of 474 hydromagnesite seeds in sample GA10H2 led to a denser microstructure, resulting 475 in a considerable strength improvement in sample GA10H2, which was in line with 476 the porosity results. The microstructural image of hydromagnesite, shown in Fig. 47710 (c), confirmed the growth of the hydrate phases (i.e. possibly C-(A)-S-H, as 478 indicated by XRD and FTIR results) around the rosette-like hydromagnesite 479 crystals, which grew and covered the surfaces of other particles. Previous studies 480 [62] reported that the adsorption force between $\mathrm{Ca}^{2+}$ ions and calcite $\left(\mathrm{CaCO}_{3}\right)$ was 481 a moderately strong acid-base (donor-acceptor) interaction, identified as an ionic482 covalent bond. This interaction was mainly related with the active surface sites 483 resulting from the presence of $\mathrm{CO}_{3}{ }^{2-}$ in calcite, although its solubility was relatively 484 low [63]. Therefore, it can also be inferred that the interaction between $\mathrm{Ca}^{2+}$ ions 485 and hydromagnesite could also be based on an ionic-covalent bond due to the 486 presence of $\mathrm{CO}_{3}{ }^{2-}$ in hydromagnesite $\left(4 \mathrm{MgCO}_{3} \cdot \mathrm{Mg}(\mathrm{OH})_{2} \cdot 4 \mathrm{H}_{2} \mathrm{O}\right)$. Accordingly, $487 \mathrm{Ca}^{2+}$ ions were first chemically adsorbed via a strong force, which led to a reduction 488 in their mobility, resulting in the formation of "stable nuclei". This was followed by 489 the precipitation of the $\mathrm{C}-(\mathrm{A})-\mathrm{S}-\mathrm{H}$ gel on the surface of these nuclei, during which $490 \mathrm{Ca}^{2+}$ ions could establish a connection between the formed $\mathrm{C}-(\mathrm{A})-\mathrm{S}-\mathrm{H}$ gel and the 491 hydromagnesite particles by ionic-covalent bonds. 
496 In addition to its role as a nucleation seed, the dissolution of hydromagnesite may 497 affect the $\mathrm{pH}$ of the solution and hence influence the hydration process. To 498 eliminate any such concern, a comparison of the $\mathrm{pH}$ values of the activator solution 499 with and without the addition of $2 \%$ hydromagnesite seeds was shown in Fig. 11. 500 These measurements reveled stable $\mathrm{pH}$ values across the two solutions, indicating 501 that hydromagnesite particles mainly acted as nucleation sites. This was also 502 confirmed by the low $\mathrm{pH}$ of the pure hydromagnesite solution, showing that the 503 majority of hydromagnesite particles remained undissolved when incorporated in 504 the activator solution.

\section{Discussion}

508

Heterogeneous nucleation can occur through the seeding of the nuclei of new phases into the existing phases, due to a lower free energy barrier [64, 65]. Accordingly, two types of heterogeneous nucleation and associated growth of hydrate phases were expected to take place simultaneously within the seeded AAS samples prepared in this study: (i) Hydration that started on the surfaces of the original slag particles, and (ii) additional hydration that started on the surfaces of hydromagnesite seeds distributed amongst the large pores in AAS blends. In 516 line with this expectation, Fig. 12 shows a schematic representation of the hydration process in samples $\mathrm{GA} 10 \mathrm{H} 0$ and $\mathrm{GA} 10 \mathrm{H} 2$. After several days of curing, unseeded samples $(\mathrm{GA} 10 \mathrm{H} 0)$ experienced a restriction of further nucleation and 519 growth via the initial formation of a thick dense layer of hydrate phases, leaving a large quantity of capillary pores within the microstructure. This constraint led to a 521 large porosity and inferior strength in comparison to seeded samples (GA10H2), 522 in which the hydrate phases (e.g. C-(A)-S-H gel) nucleated both on the original 523 particle surfaces as well as the seeds. When compared to the unseeded samples, 524 the addition of seeds into AAS blends provided an increased amount of nuclei for 525 the precipitation of additional hydrate phases, thereby greatly reducing the 526 induction time for hydration. This advancement in the hydration process increased 
527 the reaction kinetics, which was beneficial for strength development. The 528 nucleation of hydrate phases between the pores not only accelerated the hydration 529 rate and increased the overall hydration degree, but also led to denser 530 microstructures. These findings were in line with the seeding mechanisms 531 previously observed in OPC, $\mathrm{C}_{3} \mathrm{~S}$ and alkali-activated slag systems $[12,13]$.

\section{Conclusion}

This study demonstrated the effect of seeding in the acceleration of the hydration

537 kinetics of AAS blends by investigating the role of different amounts of 538 hydromagnesite as nucleation seeds. Within the seed content range (i.e. $1-5 \%$ of 539 the binder content by mass) used in this study, the introduction of $2 \%$ 540 hydromagnesite seeds proved to be effective in accelerating the hydration kinetics 541 and increasing the overall hydration degree of the prepared blends. This was 542 enabled via the continuation of hydration on the surface of the original binder as 543 well as the seeds. The improvement observed in the hydration process led to fast 544 setting within AAS blends, which translated into a dense microstructure via the 545 widespread precipitation of hydrate phases (e.g. C-(A)-S-H). When compared to 546 unseeded samples, the increase in the formation of crosslinked C-(A)-S-H was 547 responsible for the high strengths achieved by the seeded samples.

549 Overall, the findings of this study highlighted the increased potential of AAS blends 550 to be used in cement-based applications, considering their improved mechanical 551 performance in the presence of a small amount of seeds. Its straightforward 552 incorporation into the initial mix design, ease of application, lack of any safety 553 concerns and lower cost when compared with alternatives (e.g. synthesized C-S$554 \mathrm{H}$ and nano materials), have led to the identification of hydromagnesite as an ideal 555 choice for enhancing the performance of AAS blends. 


\section{Acknowledgement}

559

560 The authors would like to acknowledge the financial support from the Singapore 561 MOE Academic Research Fund Tier 1 (RG 95/16) for the completion of this 562 research project. 


\section{References}

[1] B. Lothenbach, K. Scrivener, R. Hooton, Supplementary cementitious materials, Cement and Concrete Research 41(12) (2011) 1244-1256.

[2] M. Samarakoon, P. Ranjith, T. Rathnaweera, M. Perera, Recent advances in alkaline cement binders: A review, Journal of Cleaner Production (2019).

[3] G. Kastiukas, S. Ruan, S. Liang, X. Zhou, Development of precast geopolymer concrete via oven and microwave radiation curing with an environmental assessment, Journal of Cleaner Production (2020) 120290.

[4] G. Gu, F. Xu, S. Ruan, X. Huang, J. Zhu, C. Peng, Influence of precast foam on the pore structure and properties of fly ash-based geopolymer foams, Construction and Building Materials 256 (2020) 119410.

[5] B. Panda, S. Ruan, C. Unluer, M.J. Tan, Improving the 3D printability of high volume fly ash mixtures via the use of nano attapulgite clay, Composites Part B: Engineering 165 (2019) 75-83.

[6] B. Panda, S. Ruan, C. Unluer, M.J. Tan, Investigation of the properties of alkaliactivated slag mixes involving the use of nanoclay and nucleation seeds for $3 \mathrm{D}$ printing, Composites Part B: Engineering (2020) 107826.

[7] Y. Jin, D. Stephan, Z. Lu, The effects of calcium formate on the early hydration of alkali silicate activated slag, Materials and Structures 52(2) (2019) 37.

[8] F. Matalkah, T. Salem, M. Shaafaey, P. Soroushian, Drying shrinkage of alkali activated binders cured at room temperature, Construction and Building Materials 201 (2019) 563-570.

[9] A.S. De Vargas, D.C. Dal Molin, A.C. Vilela, F.J. Da Silva, B. Pavao, H. Veit, The effects of $\mathrm{Na}_{2} \mathrm{O} / \mathrm{SiO}_{2}$ molar ratio, curing temperature and age on compressive strength, morphology and microstructure of alkali-activated fly ash-based geopolymers, Cement and Concrete Composites 33(6) (2011) 653-660.

[10] B.S. Gebregziabiher, R. Thomas, S. Peethamparan, Very early-age reaction kinetics and microstructural development in alkali-activated slag, Cement and Concrete Composites 55 (2015) 91-102. 
[11] T. Meng, Y. Hong, H. Wei, Q. Xu, Effect of nano-SiO2 with different particle size on the hydration kinetics of cement, Thermochimica Acta 675 (2019) 127-133. [12] J.J. Thomas, H.M. Jennings, J.J. Chen, Influence of nucleation seeding on the hydration mechanisms of tricalcium silicate and cement, The Journal of Physical Chemistry C 113(11) (2009) 4327-4334.

[13] M.H. Hubler, J.J. Thomas, H.M. Jennings, Influence of nucleation seeding on the hydration kinetics and compressive strength of alkali activated slag paste, Cement and Concrete Research 41(8) (2011) 842-846.

[14] S. Puligilla, X. Chen, P. Mondal, Does synthesized CSH seed promote nucleation in alkali activated fly ash-slag geopolymer binder?, Materials and Structures 52(4) (2019) 65.

[15] W. Hunnicutt, L. Struble, P. Mondal, Effect of synthesis procedure on carbonation of calcium-silicate-hydrate, Journal of the American Ceramic Society 100(8) (2017) 3736-3745.

[16] R. Maddalena, K. Li, P.A. Chater, S. Michalik, A. Hamilton, Direct synthesis of a solid calcium-silicate-hydrate (CSH), Construction and Building Materials 223 (2019) 554-565.

[17] G. Land, D. Stephan, The influence of nano-silica on the hydration of ordinary Portland cement, Journal of Materials Science 47(2) (2012) 1011-1017.

[18] C.A. Rees, J.L. Provis, G.C. Lukey, J.S. van Deventer, The mechanism of geopolymer gel formation investigated through seeded nucleation, Colloids and Surfaces A: Physicochemical and Engineering Aspects 318(1-3) (2008) 97-105.

[19] Z. Wu, C. Shi, K.H. Khayat, S. Wan, Effects of different nanomaterials on hardening and performance of ultra-high strength concrete (UHSC), Cement and Concrete Composites 70 (2016) 24-34.

[20] M. Morsy, S. Alsayed, M. Aqel, Effect of nano-clay on mechanical properties and microstructure of ordinary Portland cement mortar, International Journal of Civil and Environmental Engineering 10(01) (2010) 23-27.

[21] M. Morsy, Y. Al-Salloum, H. Abbas, S. Alsayed, Behavior of blended cement mortars containing nano-metakaolin at elevated temperatures, Construction and Building materials 35 (2012) 900-905. 
[22] M.M. Norhasri, M. Hamidah, A.M. Fadzil, Applications of using nano material in concrete: A review, Construction and Building Materials 133 (2017) 91-97.

[23] N. Dung, C. Unluer, Performance of reactive MgO concrete under increased $\mathrm{CO}_{2}$ dissolution, Cement and Concrete Research (2019).

[24] N. Dung, C. Unluer, Development of MgO concrete with enhanced hydration and carbonation mechanisms, Cement and Concrete Research 103 (2018).

[25] N. Dung, C. Unluer, Influence of nucleation seeding on the performance of carbonated MgO formulations, Cement and Concrete Composites 83 (2017) 1-9. [26] S. Ghosh, Nanomaterials Safety: Toxicity And Health Hazards, Walter de Gruyter GmbH \& Co KG2018.

[27] G. Wakefield, Nanomaterials: costs and opportunities, Nano Today 3(3-4) (2008) 48.

[28] N. Dung, T. Hooper, C. Unluer, Accelerating the reaction kinetics and improving the performance of $\mathrm{Na}_{2} \mathrm{CO}_{3}$-activated GGBS mixes, Cement and Concrete Research 126 (2019) 105927.

[29] Y. Zhang, R.A. Dawe, Influence of $\mathrm{Mg}^{2+}$ on the kinetics of calcite precipitation and calcite crystal morphology, Chemical Geology 163(1-4) (2000) 129-138.

[30] Q. Li, Y. Ding, G. Yu, C. Li, F. Li, Y. Qian, Fabrication of light-emitting porous hydromagnesite with rosette-like architecture, Solid State Communications 125(2) (2003) 117-120.

[31] G.W. Beall, E.-S.M. Duraia, F. El-Tantawy, F. Al-Hazmi, A.A. Al-Ghamdi, Rapid fabrication of nanostructured magnesium hydroxide and hydromagnesite via microwave-assisted technique, Powder Technology 234 (2013) 26-31.

[32] J.W. Anthony, R.A. Bideaux, K.W. Bladh, M.C. Nichols, Handbook of mineralogy, Mineralogical Society of America. Mineral Data Publishing, Chantilly. USA, 1995.

[33] C. Kuenzel, F. Zhang, V. Ferrandiz-Mas, C. Cheeseman, E. Gartner, The mechanism of hydration of $\mathrm{MgO}$-hydromagnesite blends, Cement and Concrete Research 103 (2018) 123-129. 
[34] F. Winnefeld, E. Epifania, F. Montagnaro, E.M. Gartner, Further studies of the hydration of MgO-hydromagnesite blends, Cement and Concrete Research 126 (2019) 105912.

[35] S. Ruan, C. Unluer, Influence of mix design on the carbonation, mechanical properties and microstructure of reactive $\mathrm{MgO}$ cement-based concrete, Cement and Concrete Composites 80 (2017) 104-114.

[36] S. Ruan, C. Unluer, Influence of supplementary cementitious materials on the performance and environmental impacts of reactive magnesia cement concrete, Journal of Cleaner Production 159 (2017) 62-73.

[37] S. Ruan, J. Liu, E.-H. Yang, C. Unluer, Performance and microstructure of calcined dolomite and reactive magnesia-based concrete samples, Journal of Materials in Civil Engineering 29(12) (2017) 04017236.

[38] S. Ruan, C. Unluer, Effect of air entrainment on the performance of reactive MgO and PC mixes, Construction and Building Materials 142 (2017) 221-232.

[39] ASTM, C1702-17, Standard test method for measurement of heat of hydration of hydraulic cementitious materials using isothermal conduction calorimetry, ASTM Committee C01, West Conshohocken, PA 19428-2959, United States, 2017.

[40] ASTM, C191-08, Standard test methods for time of setting of hydraulic cement by Vicat needle, ASTM, Annual Book of ASTM Standards 4 (2019).

[41] Q. Zeng, X. Wang, P. Yang, J. Wang, C. Zhou, Tracing mercury entrapment in porous cement paste after mercury intrusion test by X-ray computed tomography and implications for pore structure characterization, Materials Characterization 151 (2019) 203-215.

[42] W. Zhu, X. Chen, L.J. Struble, E.-H. Yang, Characterization of calciumcontaining phases in alkali-activated municipal solid waste incineration bottom ash binder through chemical extraction and deconvoluted Fourier transform infrared spectra, Journal of Cleaner Production 192 (2018) 782-789.

[43] ASTM, C25-06. Standard test methods for chemical analysis of limestone, quicklime and hydrated lime, ASTM International, West Conshohocken, PA, Vol. 10, 2019. 
[44] X. Ke, S.A. Bernal, J.L. Provis, Controlling the reaction kinetics of sodium carbonate-activated slag cements using calcined layered double hydroxides, Cement and Concrete Research 81(Supplement C) (2016) 24-37.

[45] M. Nehdi, Why some carbonate fillers cause rapid increases of viscosity in dispersed cement-based materials, Cement and Concrete Research 30(10) (2000) 1663-1669.

[46] Q. Zeng, X. Wang, P. Yang, J. Wang, C. Zhou, Tracing mercury entrapment in porous cement paste after mercury intrusion test by X-ray computed tomography and implications for pore structure characterization, Materials Characterization (2019).

[47] A. Choudhary, V. Shah, S. Bishnoi, Effect of low cost fillers on cement hydration, Construction and Building Materials 124 (2016) 533-543.

[48] N. Cristelo, J. Coelho, T. Miranda, Á. Palomo, A. Fernández-Jiménez, Alkali activated composites-An innovative concept using iron and steel slag as both precursor and aggregate, Cement and Concrete Composites 103 (2019) 11-21.

[49] A. Abdalqader, F. Jin, A. Al-Tabbaa, Performance of magnesia-modified sodium carbonate-activated slag/fly ash concrete, Cement and Concrete Composites 103 (2019) 160-174.

[50] F. Jin, K. Gu, A. Al-Tabbaa, Strength and drying shrinkage of reactive MgO modified alkali-activated slag paste, Construction and Building Materials 51 (2014) 395-404.

[51] S.A. Bernal, J.L. Provis, B. Walkley, R. San Nicolas, J.D. Gehman, D.G. Brice, A.R. Kilcullen, P. Duxson, J.S.J. van Deventer, Gel nanostructure in alkaliactivated binders based on slag and fly ash, and effects of accelerated carbonation, Cement and Concrete Research 53 (2013) 127-144.

[52] A.F. Abdalqader, F. Jin, A. Al-Tabbaa, Characterisation of reactive magnesia and sodium carbonate-activated fly ash/slag paste blends, Construction and Building Materials 93 (2015) 506-513.

[53] I.G. Lodeiro, D.E. Macphee, A. Palomo, A. Fernández-Jiménez, Effect of alkalis on fresh C-S-H gels. FTIR analysis, Cement and Concrete Research 39(3) (2009) 147-153. 
[54] M. Criado, A. Fernández-Jiménez, A. Palomo, Alkali activation of fly ash: Effect of the $\mathrm{SiO}_{2} / \mathrm{Na}_{2} \mathrm{O}$ ratio: Part I: FTIR study, Microporous and Mesoporous Materials 106(1-3) (2007) 180-191.

[55] E. Kapeluszna, Ł. Kotwica, A. Różycka, Ł. Gołek, Incorporation of Al in CASH gels with various $\mathrm{Ca} / \mathrm{Si}$ and $\mathrm{Al} / \mathrm{Si}$ ratio: Microstructural and structural characteristics with DTA/TG, XRD, FTIR and TEM analysis, Construction and Building Materials 155 (2017) 643-653.

[56] R.J. Kirkpatrick, J. Yarger, P.F. McMillan, Y. Ping, X. Cong, Raman spectroscopy of $\mathrm{CSH}$, tobermorite, and jennite, Advanced Cement Based Materials 5(3-4) (1997) 93-99.

[57] I. García-Lodeiro, A. Fernández-Jiménez, M.T. Blanco, A. Palomo, FTIR study of the sol-gel synthesis of cementitious gels: $\mathrm{C}-\mathrm{S}-\mathrm{H}$ and $\mathrm{N}-\mathrm{A}-\mathrm{S}-\mathrm{H}$, Journal of Sol-Gel Science and Technology 45(1) (2008) 63-72.

[58] Z. Zhang, Y. Zhu, H. Zhu, Y. Zhang, J.L. Provis, H. Wang, Effect of drying procedures on pore structure and phase evolution of alkali-activated cements, Cement and Concrete Composites 96 (2019) 194-203.

[59] W. Zhu, X. Chen, L.J. Struble, E.-H. Yang, Quantitative characterization of aluminosilicate gels in alkali-activated incineration bottom ash through sequential chemical extractions and deconvoluted nuclear magnetic resonance spectra, Cement and Concrete Composites (2019).

[60] W. Zhu, X. Chen, A. Zhao, L.J. Struble, E.-H. Yang, Synthesis of high strength binders from alkali activation of glass materials from municipal solid waste incineration bottom ash, Journal of Cleaner Production 212 (2019) 261-269.

[61] A. Fernández-Jiménez, F. Puertas, I. Sobrados, J. Sanz, Structure of calcium silicate hydrates formed in alkaline-activated slag: influence of the type of alkaline activator, Journal of the American Ceramic Society 86(8) (2003) 1389-1394.

[62] X. Ouyang, D. Koleva, G. Ye, K. van Breugel, Understanding the adhesion mechanisms between CSH and fillers, Cement and Concrete Research 100 (2017) 275-283. 
[63] Y.C. Huang, F.M. Fowkes, T.B. Lloyd, N.D. Sanders, Adsorption of calcium ions from calcium chloride solutions onto calcium carbonate particles, Langmuir 7(8) (1991) 1742-1748.

[64] Q. Zeng, A simple method for estimating the size of nuclei on fractal surfaces, Journal of Crystal Growth 475 (2017) 49-54.

[65] Q. Zeng, S. Xu, Thermodynamics and characteristics of heterogeneous nucleation on fractal surfaces, The Journal of Physical Chemistry C 119(49) (2015) 27426-27433. 


\section{List of Tables}

Table 1 The chemical composition (wt.\%) of GGBS.

\begin{tabular}{ccccccccc}
\hline & $\mathrm{MgO}$ & $\mathrm{CaO}$ & $\mathrm{SiO}_{2}$ & $\mathrm{Fe}_{2} \mathrm{O}_{3}$ & $\mathrm{Al}_{2} \mathrm{O}_{3}$ & $\mathrm{R}_{2} \mathrm{O}_{3}$ & $\mathrm{~K}_{2} \mathrm{O}$ & $\mathrm{TiO}_{2}$ \\
\hline GGBS & 9.3 & 37.8 & 32.3 & 0.5 & 14.6 & - & - & - \\
\hline
\end{tabular}


Table 2 The mix designs used in this study.

\begin{tabular}{ccc}
\hline Sample & Activator content (\%) & Hydromagnesite seed content (\%) \\
\hline GA0H0 & 0 & 0 \\
GA10H0 & 10 & 0 \\
GA10H2 & 10 & 2 \\
\hline
\end{tabular}


Table 3 Summary of mass loss obtained at various stages by TGA-DSC after 14 days of curing.

\begin{tabular}{ccccc}
\hline \multirow{2}{*}{ Sample } & $30-220^{\circ} \mathrm{C}$ & $220-730^{\circ} \mathrm{C}$ & $730-900^{\circ} \mathrm{C}$ & \\
\cline { 2 - 4 } & $\begin{array}{c}\text { Dehydration of } \\
\mathrm{C}-(\mathrm{A})-\mathrm{S}-\mathrm{H}\end{array}$ & $\begin{array}{c}\text { Decomposition } \\
\text { of hydrotalcite }\end{array}$ & $\begin{array}{c}\text { Decarbonation of } \\
\text { carbonates }\end{array}$ & Total \\
\hline $\mathrm{GA0H0}$ & 4.2 & 3.7 & & \\
$\mathrm{GA10H0}$ & 5.4 & 5.1 & 1.3 & 9.2 \\
$\mathrm{GA10H} 2$ & 12.4 & 7.0 & 0.7 & 11.5 \\
\hline
\end{tabular}


Table 4 FTIR spectral deconvolution of the hydrate phase in samples GA10H0 and $\mathrm{GA} 10 \mathrm{H} 2$, provided as wavenumber $\left(\mathrm{cm}^{-1}\right)$ and peak area percentage.

\begin{tabular}{ccccccc}
\hline Band & 1 & 2 & 3 & 4 & 5 & 6 \\
\hline Hydrate phase in & 840 & - & 898 & 947 & 985 & 1030 \\
sample GA10H0 & $(7.4 \%)^{\mathrm{a}}$ & & $(28.0 \%)$ & $(35.4 \%)$ & $(15.5 \%)$ & $(13.7 \%)$ \\
Hydrate phase in & 840 & 872 & 898 & 945 & 985 & 1030 \\
sample GA10H2 & $(4.3 \%)$ & $(1.4 \%)$ & $(25.1 \%)$ & $(33.5 \%)$ & $(18.8 \%)$ & $(17.0 \%)$ \\
Assignment & $\mathrm{Q}^{1}$ & $\mathrm{CO}^{2-}$ & $\mathrm{Q}^{2}$ & $\mathrm{Q}^{2}$ & $\mathrm{Q}^{2}$ & $\mathrm{Q}^{3}$ \\
\hline
\end{tabular}

a value in parentheses is the ratio of the component peak area to the broad area. ${ }^{b} \mathrm{Q}$ denotes $\mathrm{SiO}_{4}$ tetrahedron, whereas the superscripts indicate the number of other tetrahedron units attached to it. 


\section{List of Figures}

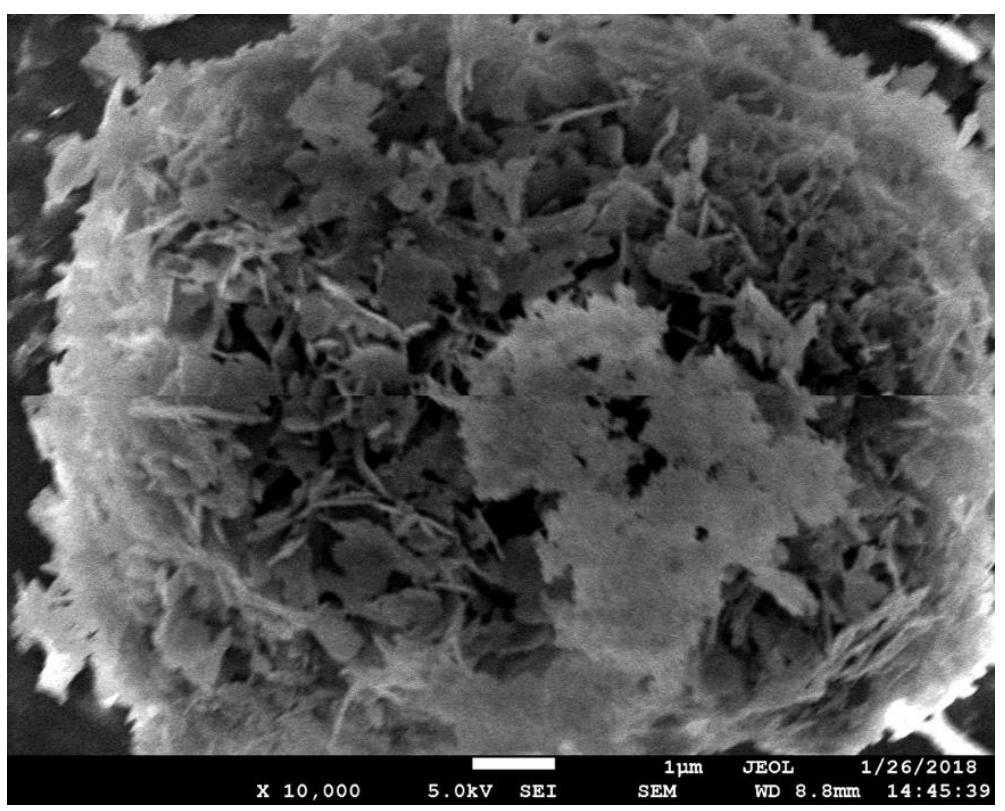

Fig. 1 SEM image of the hydromagnesite seed used in this study 


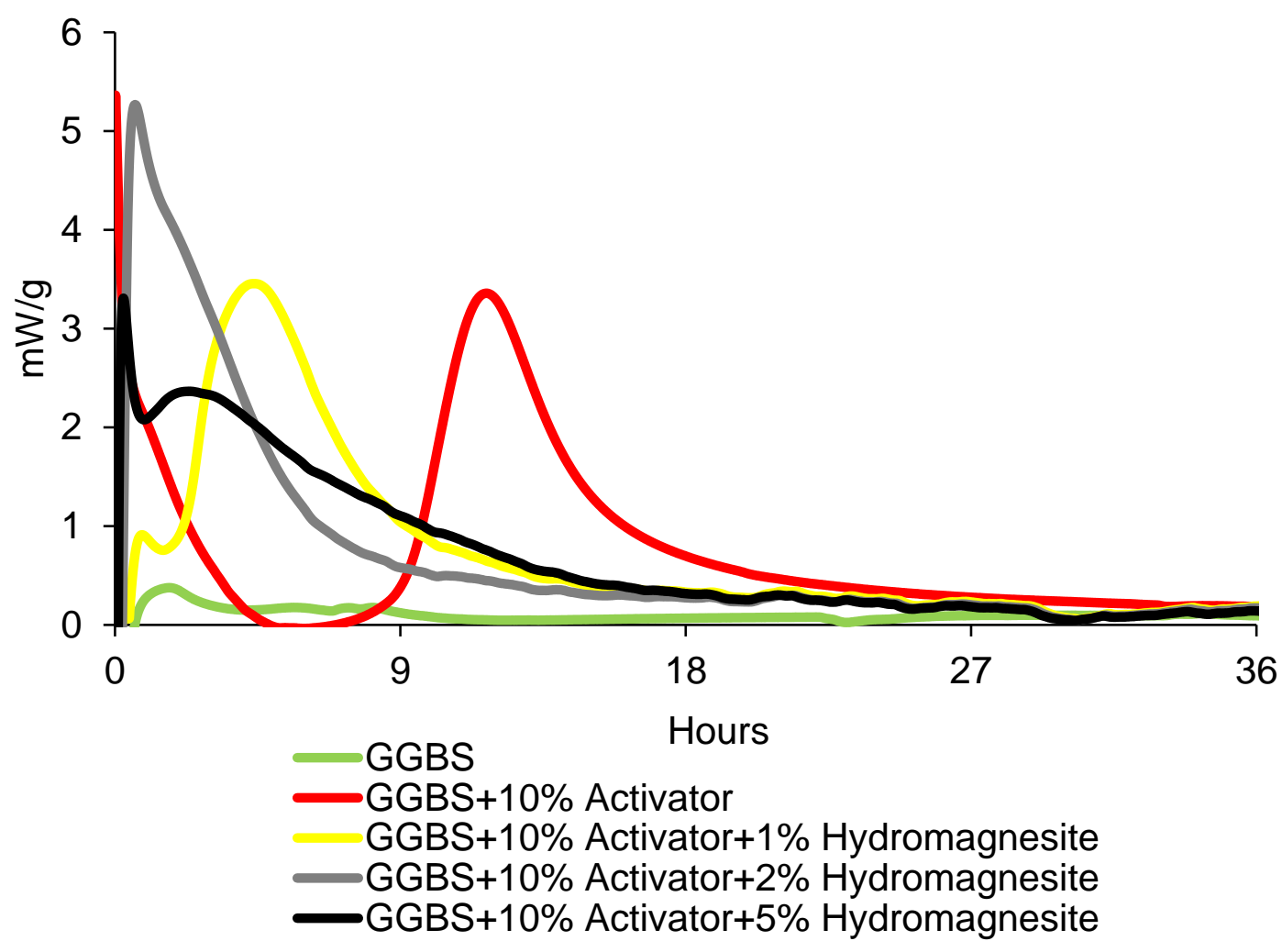

Fig. 2 Heat flow curves of AAS blends containing different amounts of hydromagnesite seed 


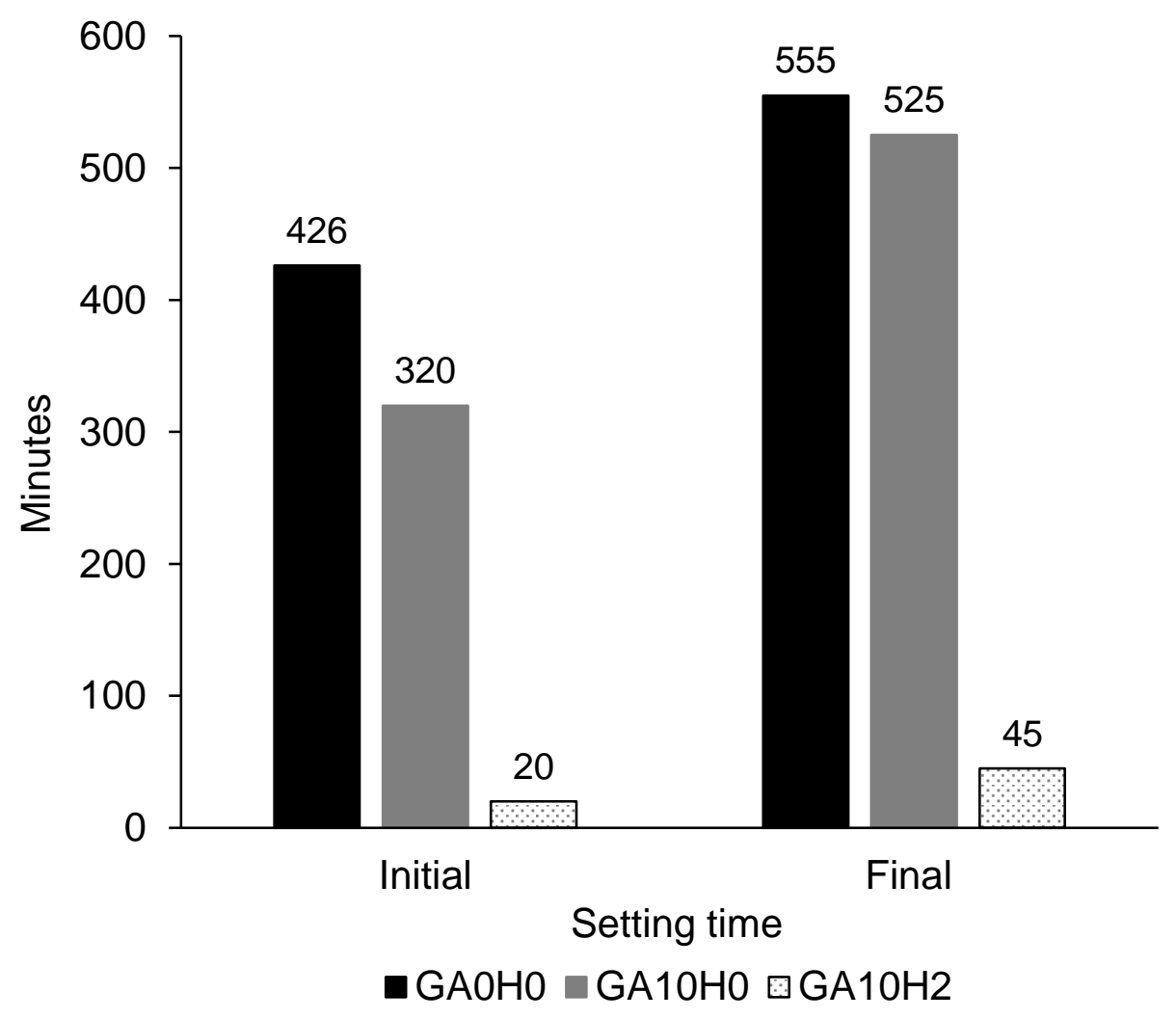

Fig. 3 The setting time of samples with varying amounts of activator and seeds 


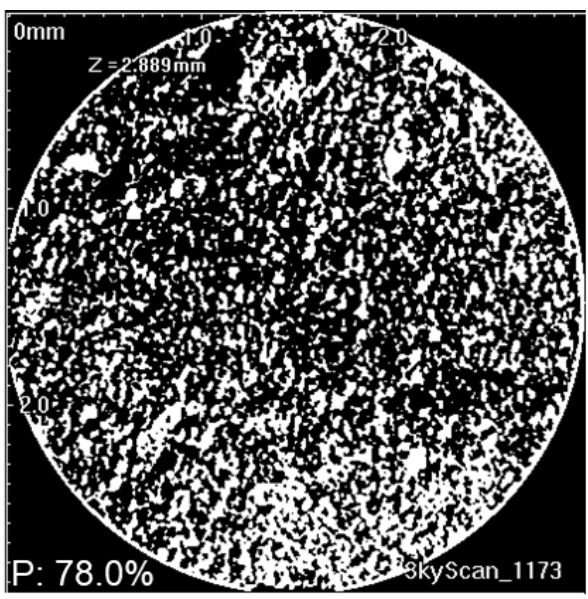

(a)

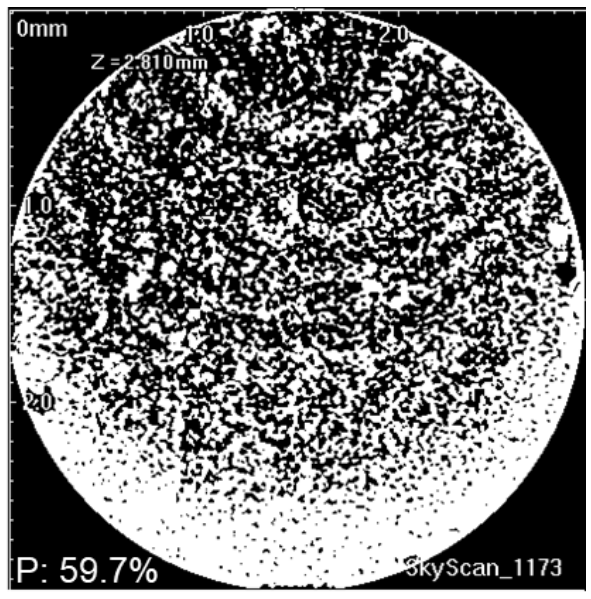

(b)

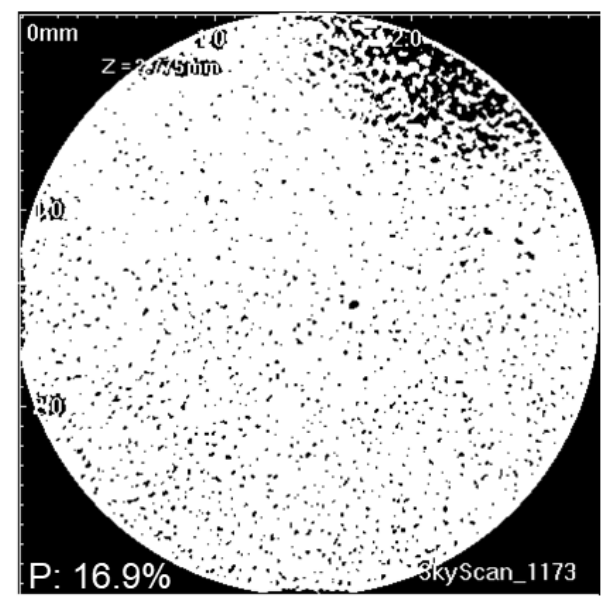

(c)

Fig. 4 Typical 2D images of cross-sections (i.e. diameter $=25 \mathrm{~mm}$, spatial resolution $=7 \mu \mathrm{m}$ ) and corresponding porosities (i.e. shown in the lower left corner of each image) of samples (a) $\mathrm{GAOH}$, (b) $\mathrm{GA} 10 \mathrm{H} 0$ and (c) $\mathrm{GA} 10 \mathrm{H} 2$ after 14 days of curing

(white area: solid phases; black area: pores) 


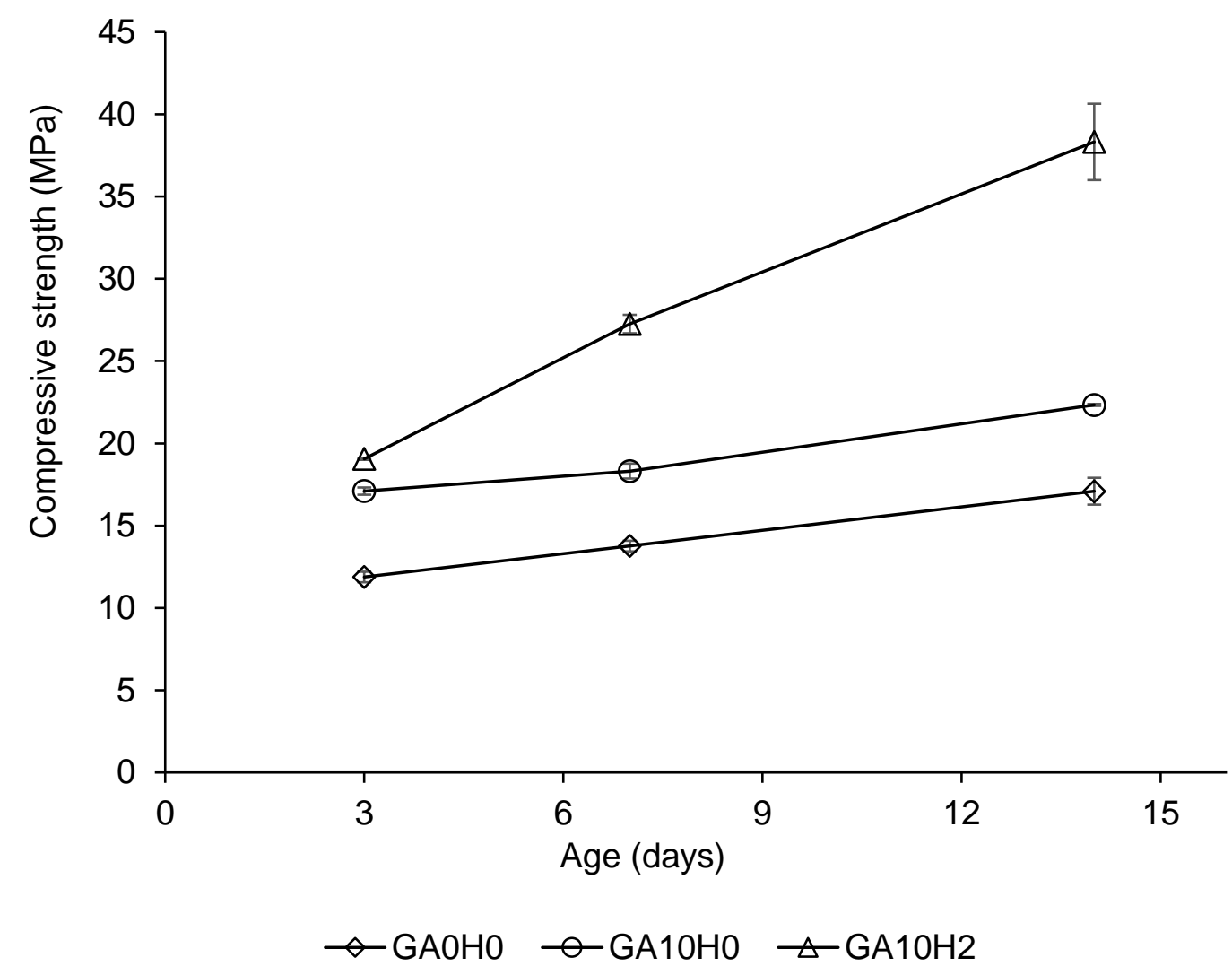

Fig. 5 Compressive strength of samples with varying amounts of activator and seeds during 14 days of curing 


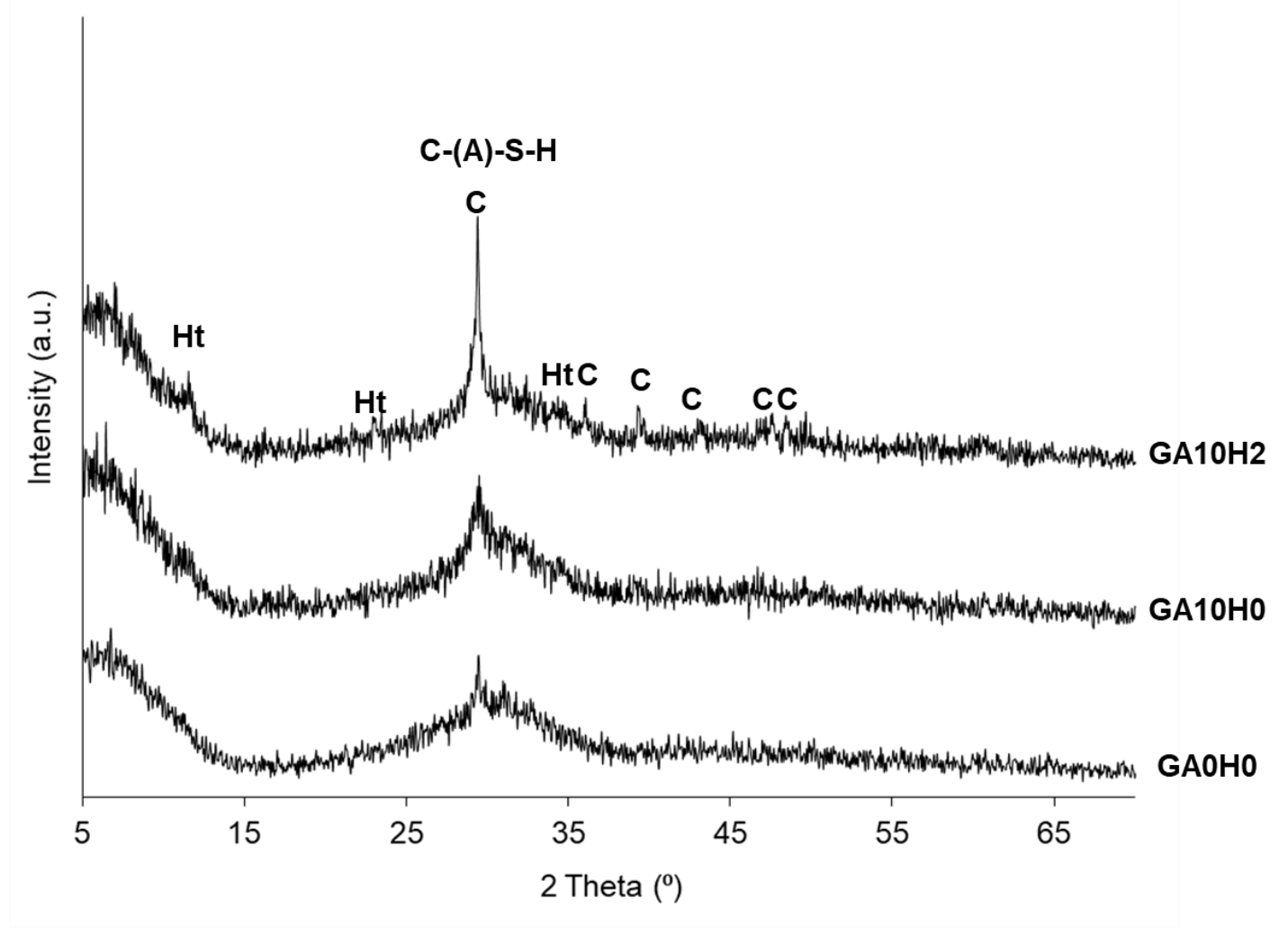

Fig. 6 XRD pattern of samples with varying amounts of activator and seeds at 14 days

(Ht: Hydrotalcite; C: Calcite; C-(A)-S-H: Calcium-(aluminate)-silicate-hydrate) 


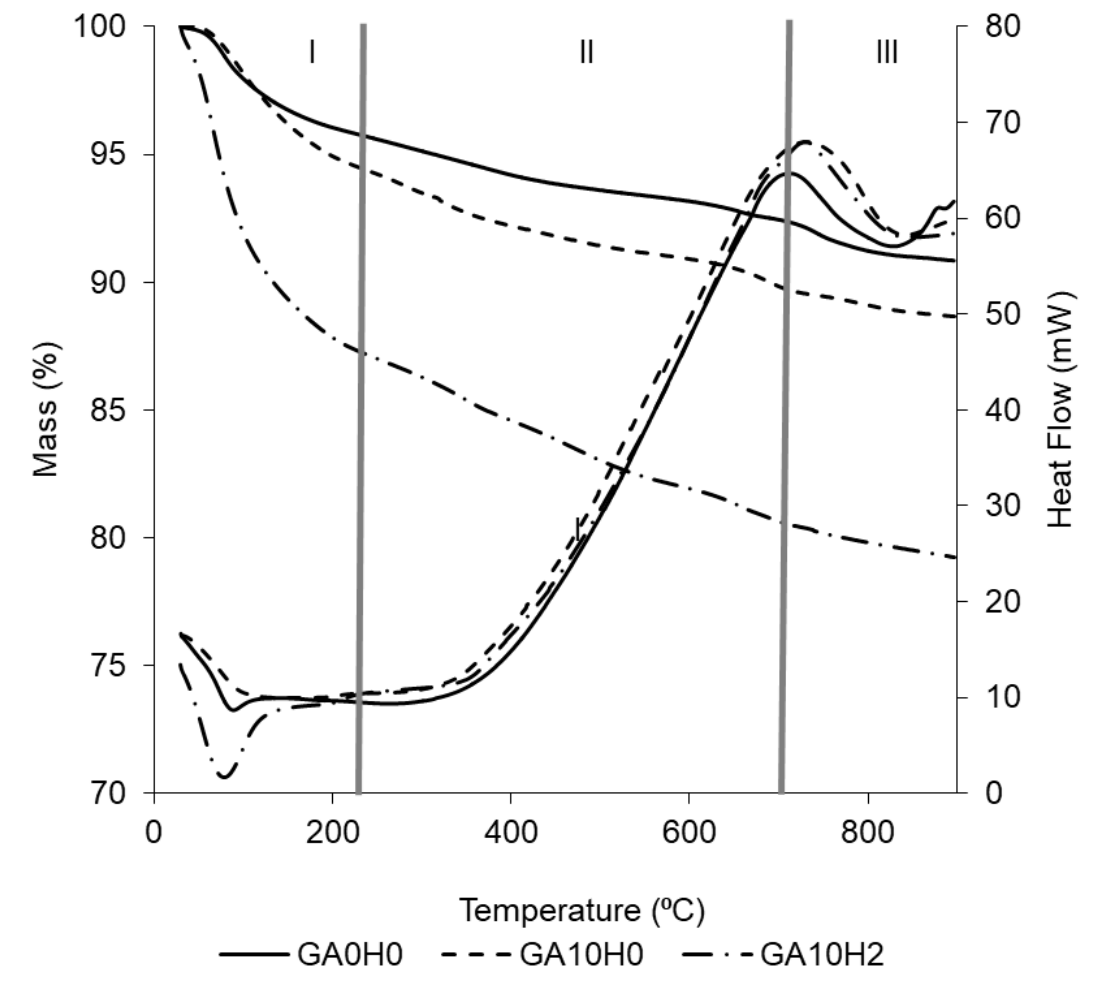

Fig. 7 TGA-DSC results of samples with varying amounts of activator and seeds at 14 days 


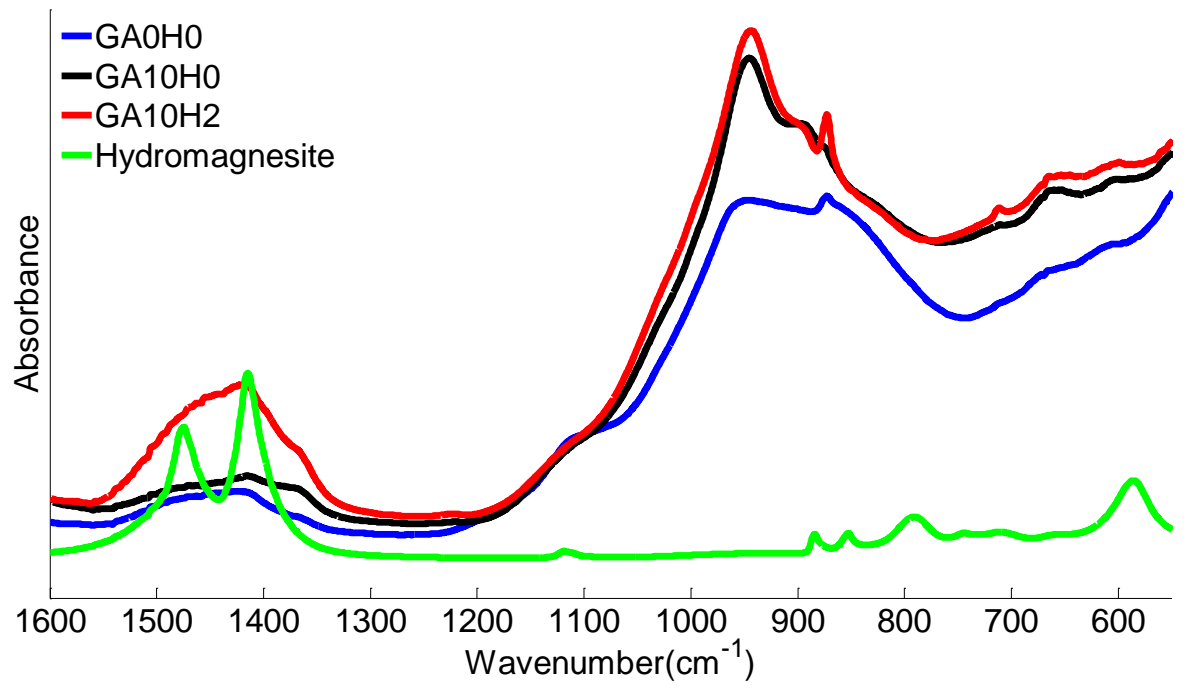

(a)

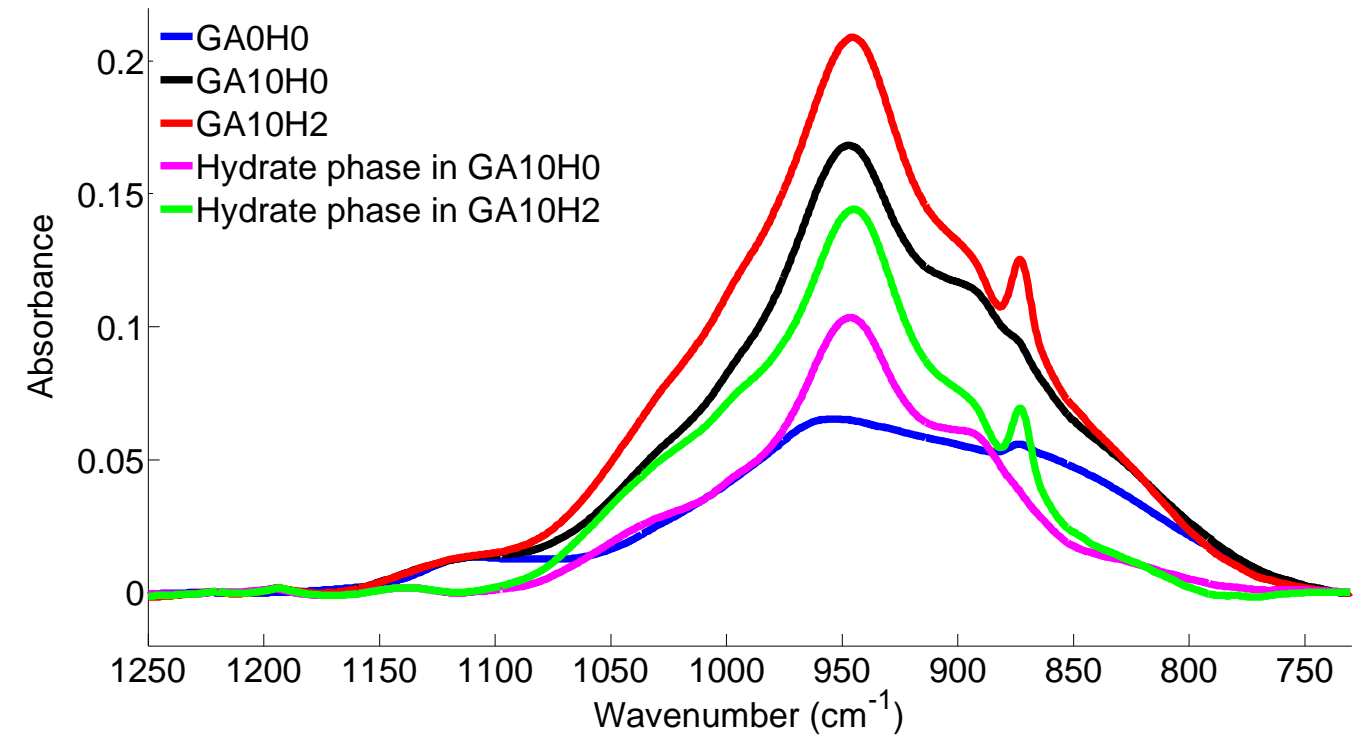

(b)

Fig. 8 FTIR spectra of (a) hydromagnesite seed and samples with varying amounts of activator and seeds and (b) subtraction of the spectra of sample $\mathrm{GA} 0 \mathrm{H} 0$ from samples $\mathrm{GA} 10 \mathrm{H} 0$ and $\mathrm{GA} 10 \mathrm{H} 2$ (i.e. after baseline correction) at 14 days 


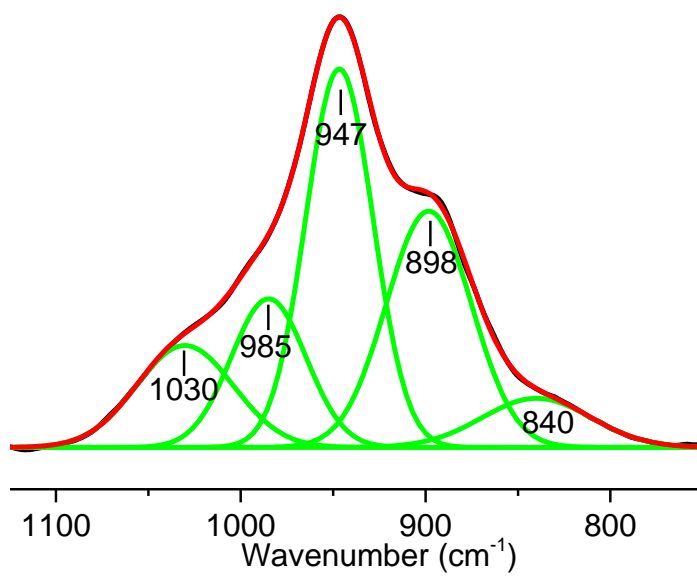

(a)

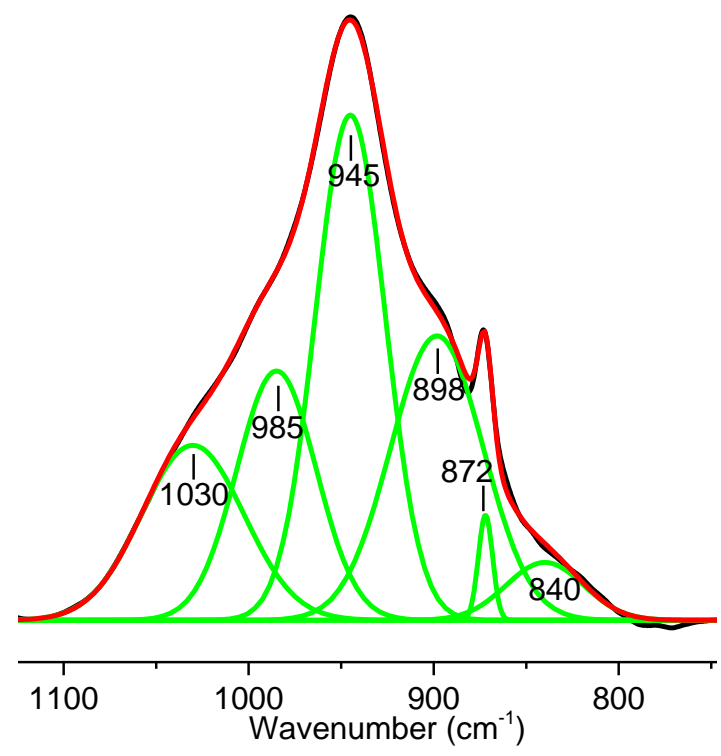

(b)

Fig. 9 Deconvoluted FTIR spectra of hydration phases in samples (a) GA10H0 and (b) $\mathrm{GA} 10 \mathrm{H} 2$

(black curve represents the original spectrum; green curves represent the bands associated with individual components; and red curve represents the sum of all the individual components) 


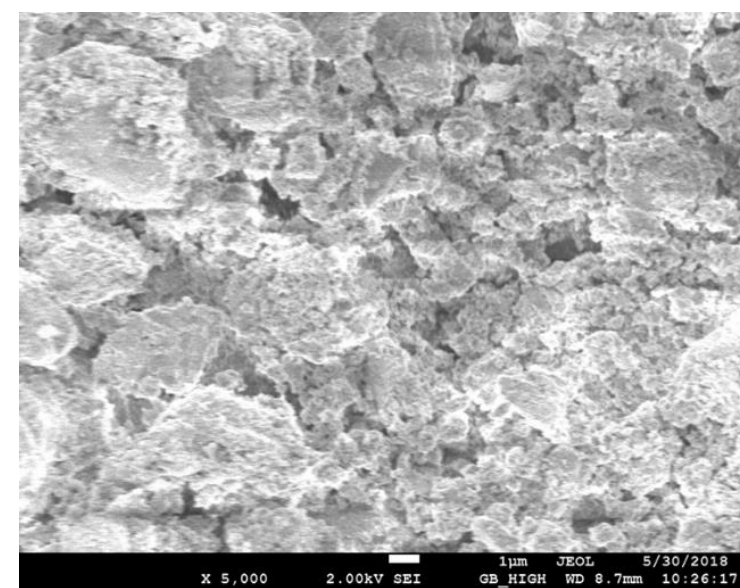

(a)

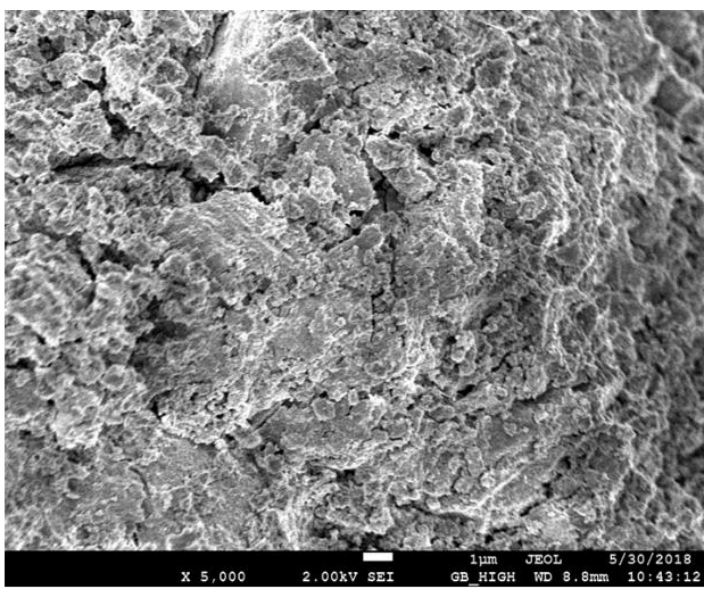

(b)

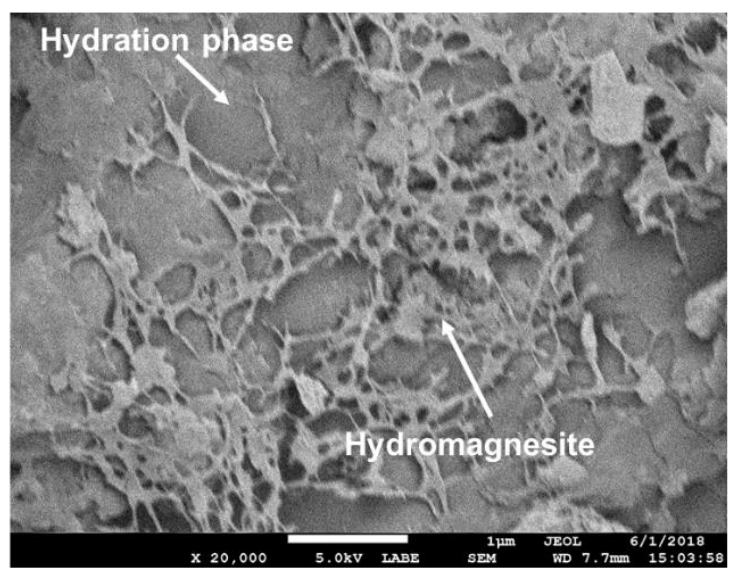

(c)

Fig. 10 Microstructural images of (a) sample GA10H0, (b) sample GA10H2 and (c) the surface of a hydromagnesite particle at 14 days 


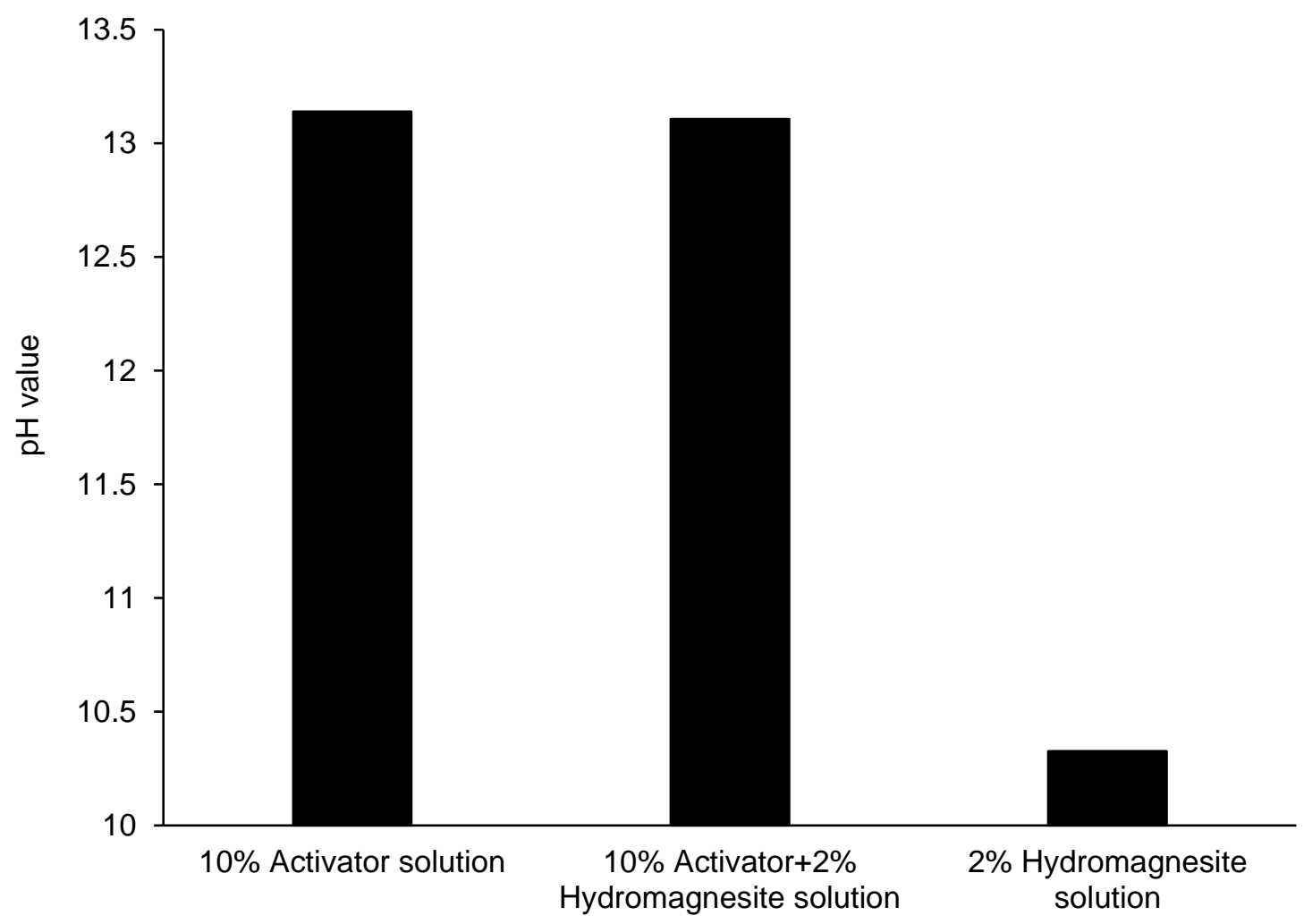

Fig. $11 \mathrm{pH}$ values of different solutions used in this study 


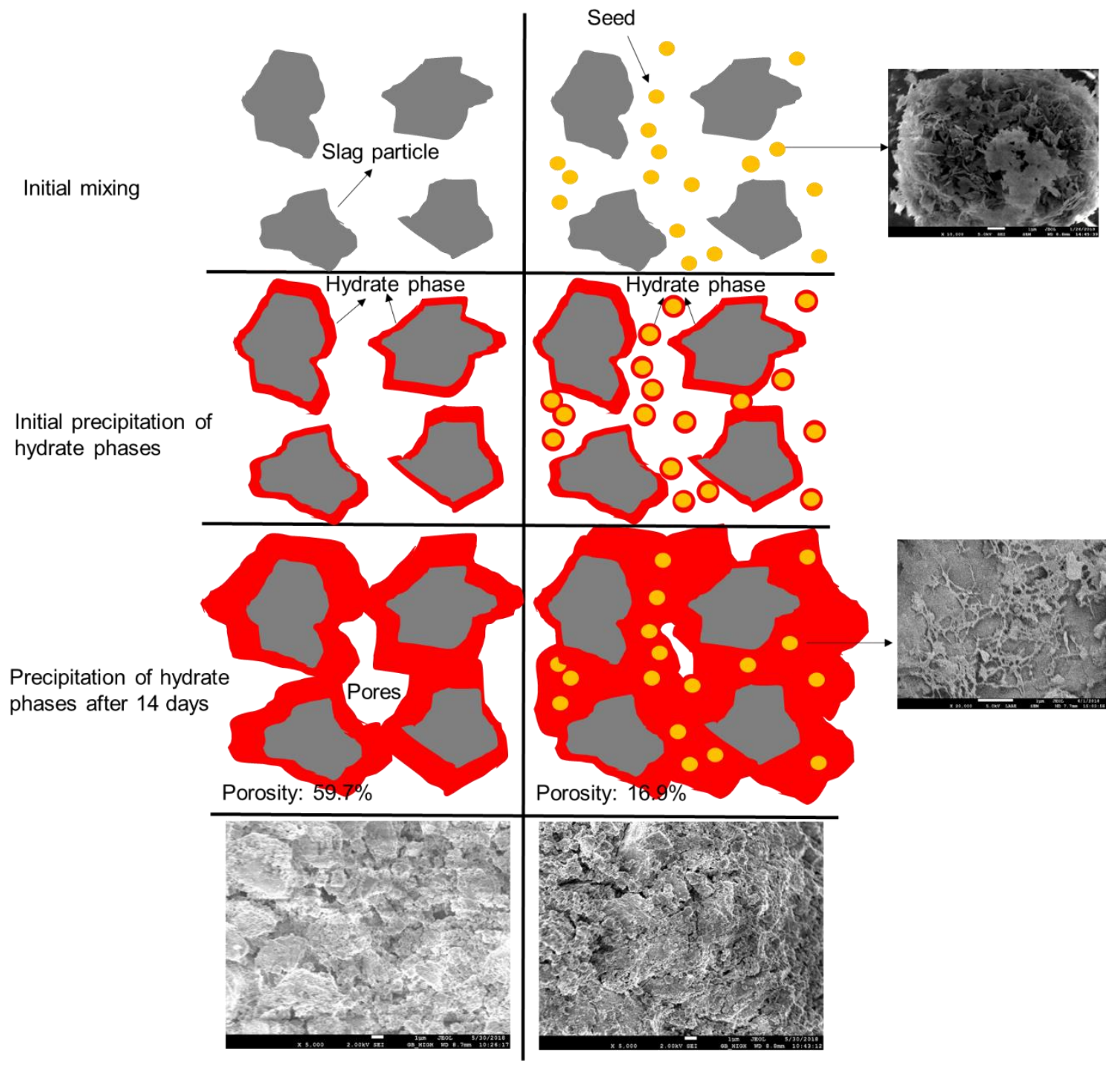

(a)

(b)

Fig. 12 Schematic representation of the hydration process in samples (a) $\mathrm{GA} 10 \mathrm{H} 0$ and (b) GA10H2 